\title{
A narrativa literária de Heródoto e Ctésias \\ : um ensaio comparativo sobre o papel social e o poder feminino na Pérsia Aquemênida dos séculos VI-V AEC
}

\author{
Matheus Moraes Maluf \\ Mestrando no Programa de Pós-Graduação em História pela \\ Universidade Federal Fluminense (UFF)
}

\section{Resumo}

Ao lermos Heródoto e Ctésias, podemos compreender que a mulher Persa, principalmente da Corte, em específico a Rainha, possuía um poder acima das demais, exercendo um papel social e político de grande influência. O presente artigo pretende analisar e ensaiar uma comparação em como esses autores helênicos representavam essas mulheres Reais através de seus textos, nas passagens em que há mais ênfase sobre o papel feminino na sociedade helênica e Corte Aquemênida.

Palavras-chave Heródoto - Ctésias - Pérsia Aquemênida - História das Mulheres - História Comparada.

Submissão

13/07/202I Aprovação

I3/09/202I Publicação

$08 / 12 / 2021$ 


\title{
The Literary Narrative of Herodotus and Ctesias: A Comparative Essay on the Social Role and Female Power in Achaemenid Persia of The VI-V Centuries BCE
}

\begin{abstract}
When reading Herodotus and Ctesias, we can understand that the Persian woman, mainly from the Court, specifically the Queen, had a power above the others, exercising a social and political role of great influence. This article intends to analyse and attempt a comparison on how these Hellenic authors represented these Royal women through their texts, in the passages where there is more emphasis on the female role in Hellenic society and the Achaemenid Court.
\end{abstract}

Keywords Herodotus - Ctesias - Achaemenid Persia - Women History - Comparative History.

\section{La narrativa literaria de Herodoto y Ctesias: ensayo comparativo sobre el papel social y poder femenino en el Imperio Aqueménida del VI-V A.E.C.}

\section{Resumen}

\begin{abstract}
Al leer a Herodoto y Ctesias podemos entender que la mujer persa, principalmente en la Corte, específicamente la Reina, tenía un poder sobre los demás, desempeñando un papel social y político de gran influencia. Este artículo pretende analizar y ensayar una comparación de cómo estos autores helénicos representaron a estas mujeres Reales a través de sus textos, en las partes donde hay más énfasis en el papel femenino en la sociedad helénica y la Corte Aqueménida.
\end{abstract}

Palabras clave Herodoto - Ctesias - Persia Aqueménida - Historia de la Mujer - Historia Comparada. 


\section{Introdução}

História Comparada ganhou forças a partir do século XX. Em um
contexto europeu de descontentamento e frustração causados pelos
nacionalismos exacerbados e pelos horrores da Primeira Grande Guerra,
autores como Marc Bloch, Lucien Febvre e Louis Davillé, para exemplificar alguns, investiram parte de seus esforços nesse método. O comparativismo surge, então, como uma forma de romper o isolamento e abrir o diálogo, contrastando elementos humanos. ${ }^{\mathrm{I}}$

Apesar de haver autores comparatistas anteriores, como Oswald Spengler e Arnold Toynbee, é com Marc Bloch, francês nascido em I886 e que viveu as duas guerras mundiais intensamente, segundo Jacques Le Goff, que a História Comparada atinge ímpeto. ${ }^{2}$ De acordo com Lilia Schwarcz,

Bloch inaugurou a noção de "história como problema". Em primeiro lugar, a história não seria mais entendida como uma "ciência do passado" uma vez que, segundo Bloch, "passado não é objeto de ciência". Ao contrário, era no jogo entre a importância do presente para a compreensão do passado e vice-versa que a partida era, de fato, jogada. Nessa formulação pretensamente simples estava exposto o "método regressivo": temas do presente condicionam e delimitam o retorno, possível, ao passado. Por isso mesmo, Bloch preferia trocar os termos da equação e provocar dizendo que, assim como a história não era ciência do passado, também não poderia ser definida como uma "ciência do homem". [...] "Documentos são vestígios", dizia Marc Bloch, contrapondo-se à versão da época, que definia o passado como um dado rígido, que ninguém altera ou modifica. [...] Segundo Bloch, mesmo o mais claro e complacente dos documentos não fala senão quando se sabe interrogá-lo. É a pergunta que fazemos que condiciona a análise e, no limite, eleva ou diminui a importância de um texto retirado de um momento afastado. Novos tempos levam a novas historicidades; boas perguntas constituem campos inesperados [...]. Nenhum objeto tem movimento na sociedade humana exceto pela significação que os homens lhe atribuem, e são as questões que condicionam os objetos e não o oposto. ${ }^{3}$

Em seu método, havia dois aspectos irredutíveis e imprescindíveis: certa similaridade dos fatos, por um lado, e certa dessemelhanças nos ambientes em que esta

I BARROS, J. D. História comparada. Petrópolis, RJ: Vozes, 2oI4. p. 7-8; THEML, N.; BUSTAMANTE, R. "História comparada: olhares plurais". Revista de História Comparada, v. I, n. I, 2007. p. 2.

2 LE GOFF, J. "Prefácio”. BLOCH, M. Apologia da história ou O ofício de historiador. Rio de Janeiro: Zahar, 2002. p. 33 .

3 SCHWARCZ, L. "Por uma historiografia da reflexão (apresentação à edição brasileira)". BLOCH, M. Apologia da história on O ofício de historiador. Rio de Janeiro: Zahar, 2002. p. 7-8. 


\section{REVISTA ANGELUS NOVUS}

similaridade ocorria, por outro. Desta maneira, se poderia comparar sociedades distantes no tempo e espaço ${ }^{4}$ ou sociedades próximas espacialmente e temporalmente. O segundo método, comparar sociedades com proximidade espacial e temporal, era o preferido de Bloch, pois isto abriria o entendimento do historiador para influências mútuas e o põem em posição favorável para questionamentos e esclarecimentos, havendo o historiador de estar apto a identificar semelhanças e diferenças. 5 É por isso que Le Goff afirma que "é preciso permanecermos fiéis ao espírito de Marc Bloch, para isso comparando tão somente o que é comparável”. ${ }^{6}$

É justamente contra o paradigma de apenas poder "comparar o comparável” que Marcel Detienne se opõem, defendendo a História Comparada de maneira inexorável. ${ }^{7}$ Detienne diz defender um comparativismo construtivo, no qual seus projetos e procedimentos devem se dar de início "como campo de exercício e de experimentação, o conjunto das representações culturais entre as sociedades do passado, tanto as mais distantes como as mais próximas, e os grupos humanos vivos sobre o planeta, ontem e hoje”, pois o comparativismo não deve ter impedimentos, podendo se deslocar como e quando quiser. ${ }^{8}$ Sendo assim, para Maria Elizabeth Bueno de Godoy e Gustavo de Andrade Durão,

Através do método comparado, Detienne também suscita a capacidade de curiosidade e de questionamento o qual o historiador deve sempre aportar. Ele se diferencia de Bloch no sentido em que abrange as barreiras do campo de análise, expandindo a comparação. O helenista, em seu livro, explicou que uma das características de seu método era comparar também o dessemelhante, o não aparentado, o estranho, pois dessa maneira era possível atingirem-se novos elementos de análise constitutivos para a pesquisa comparada. ${ }^{9}$

Deste modo, Alexandre Santos de Moraes aduz que "frente ao campo de experimentação que se descortina diante dos pesquisadores, elege-se uma configuração específica que, por sua vez, pode ser remetida a diferentes temporalidades e

4 Dentro da concepção de Bloch, sociedades distantes no tempo e espaço teriam a ausência de intercessão, havendo risco da falsa analogia e do anacronismo (BARROS, J. D. História comparada. Petrópolis, RJ: Vozes, 20I4. p. 48-49).

5 BARROS, op. cit., p. 48-50.

6 LE GOFF, J. "Prefácio”. BLOCH, M. Os reis taumaturgos. São Paulo: Companhia das Letras, 2019. p. 37.

7 MORAES, A de. "Marcel Detienne e os caminhos do comparativismo". Revista de História Comparada, v. 3, n. I, 2009. p. 2.

8 DETIENNE, M. Comparar o incomparável. Aparecida, SP: Ideias \& Letras, 2004. p. 47.

9 GODOY, M. E. de; DURÃO, G. M. D. "Helenismo, Comparação e Reflexôes no Contexto Nacional". Revista de História Comparada, v. Io, n. 2, 2016. p. 178.

$4 \cdot$ ano XII, n. 17, 202I • ISSN 2179-5487 
sociedades", ${ }^{\text {Io }}$ visto que "é impossível construir comparáveis sem experimentar". ${ }^{\text {I }}$ Isto posto, iremos utilizar a metodologia comparativa de Detienne para nossa pesquisa, visto que o mesmo declara haver um valor ético da atividade comparativa, pois,

É que ela convida a pôr em perspectiva os valores e as escolhas da sociedade à qual se pertence, seja por ter nela nascido pela graça de Deus, seja por tê-la escolhido como sua História idiossincrásica, seja ainda por ter sido levado a nela viver até tornar-se seu residente, mais ou menos assimilado, aceito ou aculturado. ${ }^{12}$

Este último caso seria o de Ctésias, autor do Pérsica, e que teria vivido na Corte de Artaxerxes II como médico, ${ }^{13}$ supostamente vendo em primeira mão aspectos da nobreza persa e os registrando em seu livro, do qual apenas fragmentos sobreviveram, graças a autores posteriores que selecionaram trechos e os interpretaram de acordo com seus próprios objetivos. ${ }^{14}$ Heródoto, por sua vez, produziu a obra chamada Histórias, coletânea de nove livros escritos durante suas viagens, nos quais "seu objetivo declarado, como ele afirma na primeira frase de seu primeiro livro, é escrever a história das Guerras Greco-Pérsicas. Mas para fazer isso, ele deve primeiro descrever a ascensão do Império Persa". ${ }^{\text {Is }}$

Com o advento das Guerras Greco-Pérsicas (490-479 AEC), os persas ficaram mais em evidência para os helenos, gerando curiosidade e tornando-se um campo rico de exploração para os autores da Hélade. Estes autores supracitados, assim como contemporâneos e posteriores a eles, abordaram também a questão feminina na Pérsia, citando mulheres e suas relações de poder, além de uma suposta poligamia dos Reis:

Todo homem possui um número de esposas (gynaikes), e um número muito maior de amantes (pallakai). ${ }^{16}$

Quando os reis persas jantam, as esposas legais ( hai gnesai gynaikes) dos reis persas sentam ao seu lado à mesa, e comem com eles. Mas quando os reis desejam se alegrar e se embebedar, mandam suas esposas embora e mandam buscar suas musicistas e concubinas (mousorgoi kai

Io MORAES, A de. "Marcel Detienne e os caminhos do comparativismo". Revista de História Comparada, v. 3, n. I, 2009. p. 5 .

II HOPKINS, J. "Prefácio: Para um comparativismo construtivo entre historiadores e antropólogos". DETIENNE, M. Comparar o incomparável. Aparecida, SP: Ideias \& Letras, 2004. p. I5.

I2 DETIENNE, M. Comparar o incomparável. Aparecida, SP: Ideias \& Letras, 2004. p. 66.

I3 LLEWELLYN-JONES, L.; ROBSON, J. Ctesias: History of Persia. Abingdon: Routledge, 2oro. p. I2.

I4 LENFANT, D. "La «décadence» du Grand Roi et les ambitions de Cyrus le Jeune: aux sources perses d'un mythe occidental?”. Revue des Études Grecques, v. II4, n. 2, 200I. p. 43 I.

Is GODLEY, A. “General Introduction”. HERODOTUS. The Persian Wars, Volume I: Books I-II. Cambridge, MA: Harvard University Press, 1920. p. ix.

I6 HERODOTUS. The Persian Wars, Volume I: Books I-II. Cambridge, MA: Harvard University Press, 1920. p. I35. 


\section{REVISTA ANGELUS NOVUS}

pallakides). Até agora, eles estão certos no que fazem, porque não admitem qualquer parte de sua licenciosidade e devassidão às suas esposas (gametai). ${ }^{17}$

Contudo, Maria Brosius nos afirma que os Reis persas eram poligâmicos, mas alerta que a documentação helênica se apressa em rotular as mulheres que não eram esposas do Rei como concubinas, mas que se deve considerar que algumas dessas mulheres foram levadas à Corte das terras do Império, sendo algumas delas, possivelmente membros da nobreza local não persa. ${ }^{18}$

Sob este prisma, iremos ensaiar uma análise comparativa de como a mulher persa da Corte Aquemênida, especificamente as Rainhas, são representadas nos textos de Heródoto e Ctésias, e como estes entendiam o papel social e político destas e o exercício de seu poder.

\section{Heródoto, Ctésias e a documentação persa na historiografia sobre a mulher Real}

Em suas Histórias, Heródoto cita diversas mulheres nas mais variadas situações, no entanto, "a mulher que aparece nos relatos de Heródoto raramente é grega. Em geral, o autor refere-se às mulheres de regiões pelas quais viajou, ou seja, Lídia, Egito, Média, Pérsia, Etiópia, Líbia, Cítia, Trácia e colônias gregas na Ásia Menor”. ${ }^{19}$ O mesmo se aplica a Ctésias, com este mencionando as mulheres da Corte Aquemênida em específico.

Ao lermos as Histórias e os fragmentos do Pérsica, podemos notar que as mulheres possuem uma esfera de influência, às vezes maior ou menor, mas sempre presentes de forma direta ou indireta nos mais diversos acontecimentos. Um exemplo em Heródoto seria a conversa de Atossa e Dario I, na qual ela o convence a atacar a Hélade ao invés dos Citas, argumentando: "Eu ouvi sobre as mulheres Laconianas e Argivas e Áticas e Coríntias, e gostaria de tê-las como criadas”. ${ }^{20}$ Já um exemplo que podemos considerar indireto, encontrado em Ctésias, segundo Nicolau de Damasco, é o sonho de Argoste, mãe de Ciro II, que diz ao seu filho: "Enquanto grávida de você, eu parecia urinar tanto, que a massa de urina tornou-se como o curso de um grande rio que inundou toda a

17 PLUTARCH. Plutarch's Moralia Il. Cambridge, MA: Harvard University Press, 1962. I40b.13, p. 309.

I8 BROSIUS, M. A History of Ancient Persia: The Achaemenid Empire. Hoboken, NJ: Wiley-Blackwell, 202I. p. IO2.

19 FERREIRA, L. de F. “A presença da mulher na obra de Heródoto”. Varia História, vol. 4, n. 7, 1988. p. 85.

20 HERODOTUS. The Persian Wars, Volume I: Books I-II. Cambridge, MA: Harvard University Press, 1920. III.I34.

$6 \cdot$ ano XII, n. I7, 202I • ISSN 2179-5487 
Ásia e fluiu até o mar”, ${ }^{21}$ o que indicaria, segundo a interpretação do sonho, que seu filho reinaria sobre a Ásia. ${ }^{22}$

Entretanto, para Lúcia de Fátima Guerra Ferreira, parece ficar sugerido que:

Dentre os vários aspectos abordados por Heródoto quanto às mulheres, destacam-se os que se referem às suas virtudes, vinganças, casamentos, prostituição, como símbolo de fraqueza e covardia, além de aspectos mais incomuns, relativos ao cotidiano das amazonas ou atuação da tirana Artemísia. ${ }^{23}$

Devemos inferir que Heródoto analisa os povos exteriores à Hélade através de um vislumbre helênico, como afirma Nathalia Monseff Junqueira em sua tese, ${ }^{24}$ porque "os logoi herodoteanos são etnocêntricos, com os gregos no centro". ${ }^{25}$

Com isto em mente, Ferreira afirma que o autor de Halicarnasso faz menção ao modelo feminino que fugiria à regra do que é ser mulher segundo sua própria concepção, pois este defenderia o conceito de mélissa, ${ }^{26}$ isto é, "a grega bem nascida, esposa esmerada, discreta e reclusa na esfera privada, que administra o óikos, casa-se jovem e sua função primordial é a geração de filhos”. ${ }^{27}$ Além disso, de acordo com Ruth Padel,

As mulheres não tinham controle sobre seus próprios casamentos, seja como filhas ou como viúvas. Elas eram fundamentais como transmissoras de propriedades, mas elas mesmas não possuíam controle sobre suas propriedades. A proteção legal de seus direitos de herança dependia efetivamente em defini-las como incapazes de atos autodeterminados..$^{28}$

A citação de Padel é interessante pois, comparativamente, a mulher ateniense contrastaria com a mulher persa. Entretanto, Violaine Cuchet nos sinaliza que a

2I Fragmento 9o. LLEWELLYN-JONES, L.; ROBSON, J. Ctesias: History of Persia. London: Routledge, 2010. p. I60-I6I.

22 É significativo realçar que a origem de Ciro II, em Heródoto, difere em alguns pontos da origem em Ctésias. Nas Histórias, Ciro II é neto do Rei Medo Astíages, que ao sonhar que perderia o trono para o filho de sua filha, manda assassinar a criança assim que nascida, mas que por estar destinada a isso, sobrevive e cresce para tomar o poder de seu avô e reinar sobre a Ásia, com sua linhagem real revelada através de suas nobres ações (HERODOTUS. The Persian Wars, Volume I: Books I-II. Cambridge, MA: Harvard University Press, I920. I.IO7-II2).

23 FERREIRA, L. de F. "A presença da mulher na obra de Heródoto". Varia História, vol. 4, n. 7, 1988. p. 85.

24 JUNQUEIRA, N. Imagens da mulher grega: Heródoto e as pinturas em contraste. Tese (Doutorado) Instituto de Filosofia e Ciências Humanas, Universidade Estadual de Campinas, Campinas, 20II. p. 28.

25 LATEINER, D. The Historical Method of Herodotus. Toronto: University of Toronto Press, 1989. p. I47.

26 FFERREIRA, op. cit., p. 87.

27 JUNQUEIRA, op. cit., p. 75 .

28 PADEL, R. "Women: Model for Possession by Greek Daemons”. CAMERON, A.; KUHRT, A. (Org.). Images of Women in Antiquity. London: Routledge, 1993. p. 4. 


\section{REVISTA ANGELUS NOVUS}

produção textual dos antigos gregos é sexista e misógina. ${ }^{29} \mathrm{Na}$ concepção política de Aristóteles, Cuchet afirma que archai politikai é traduzido como "direitos políticos", sendo a mulher não vista como cidadã, pois ela não teria direitos, mas que Aristóteles aduz que cidadãos são aqueles nascidos de dois cidadãos, ou seja, pai e mãe atenienses, criando uma ambiguidade, pois "na Atenas dos anos 330-320 AEC, a cidadania é sobretudo um estatuto que se aplica a homens e mulheres e lhes dá um direito fundamental (sob a condição de respeitarem as regras) o de produzir cidadãos dos dois sexos”, sendo, para o autor helênico, a cidadania um estatuto conectado ao reconhecimento da filiação legítima e um conjunto de funções que são privilégios também..$^{30}$

A autora francesa declara que o conceito de cidadania é mais amplo que os archai politikai, apresentando a concepção de timai (honras), o que podemos entender como privilégios e "direitos", que derivam do sexo, idade, nascimento e até mesmo adquiridos ou perdidos por decisão do povo, englobando tanto direitos políticos quanto sociais, não se reduzindo apenas ao conceito de Aristóteles:

Os indivíduos que dispunham da integralidade dos direitos ou das honras, os epitimoi, são aqueles que se comportam segundo as regras da comunidade: pertencimento a uma família identificada como ateniense, filiação legítima, concordância da idade com a função exercida, concordância do sexo com a função exercida, modo de viver conforme as regas (sophrôsunê). As mulheres cidadãs são submetidas às mesmas restrições de comportamento que os homens cidadãos, restrições de adequação de sua pessoa com as regras de atribuição das funçôes cívicas. Elas deviam ser reconhecidas como filha legítimas por seu pai cidadão, ser apresentadas na phratria do pai. Elas não podiam, por causa de seu sexo, ser juradas, bouletas ou magistradas (exceto os sacerdócios). Na medida em que elas respeitavam essas regras, dispunham de todos os timai. . $^{3}$

Então, sendo cidadãs, podendo até mesmo ter o direito de passar seu nome aos filhos - mesmo que o matronímico seja mais raro que o patronímico - ${ }^{32}$ jamais seriam tratadas como estrangeiras e escravas, de acordo com o Violaine Cuchet, ${ }^{33}$ sendo membros legítimos da casa, pois o estatuto da pessoa dependia do estatuto da oikia. As mulheres poderiam, inclusive, falar à frente dos atenienses, como a autora exemplifica com o caso de Agariste, com o sexo apenas servindo para traçar a diferença crucial entre os adultos da Atenas do século V AEC: o direito de exercer a política, podendo falar na

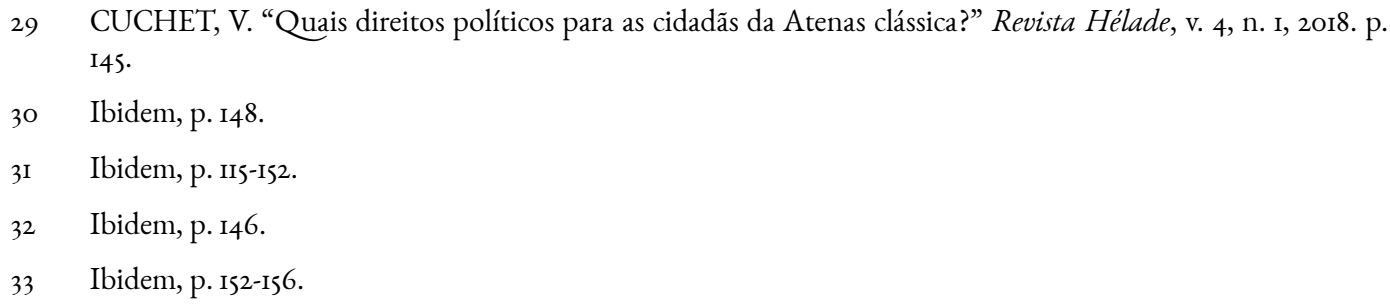

$8 \cdot$ ano XII, n. I7, 202I $・$ ISSN 2179-5487 
Assembleia, se tornar magistrado, votar e participar do exercício cívico, coisas não permitidas ao sexo feminino. Então, "Ao expandir a noção dos direitos políticos aos significados sociais das timai, o observador contemporâneo observa que, na Atenas clássica, a prática da ação pública englobava ações da vida coletiva que eram realizados, segundo os contextos, por homens e mulheres”.

Sob este prisma, podemos entender que a cidadã média ateniense, possuía tantos, ou quase tantos, direitos quanto a mulher persa, como atestado nos Tabletes da Fortificação de Persépolis, ${ }^{34}$ as quais podiam possuir propriedades, trabalhadores ao seu dispor e estarem envolvidas em atividades econômicas, fazendo elas mesmas os pedidos dos produtos ou até mesmo o Grande Rei, como Dario o faz nos PFTs 6764 e 1795, ordenando o envio de ovelhas e vinho, respectivamente, para Irtašduna. ${ }^{35}$

Os PFTs são tabuinhas de argila escritas em Elamita sobre transferências administrativas de comódites alimentícias durante os anos 509-494 AEC, cujo período corresponde do décimo terceiro ao vigésimo oitavo ano do reinado de Dario I. Essas transferências podiam ser relacionadas a grandes operações, como o transporte de um local para outro e para fins gerais, como festivais, banquetes, etc.; ou simplesmente repartir para o consumidor final, como pagamentos de trabalhadores. ${ }^{36}$ Acerca disto, Maria Brosius afirma que:

Mulheres reais também possuíam propriedades em todo o Império, o que é atestado na Pérsia, bem como no Egito, na Babilônia e Além do Rio. Elas empregavam seus próprios funcionários que gerenciavam suas propriedades, enquanto oficiais de justiça eram responsáveis pela parte administrativa e jurídica de seus negócios. Para autorizar seus pedidos em relação ao pagamento de seus trabalhadores e distribuição da produção de suas propriedades, as mulheres reais usavam seus próprios selos. Além de terras, elas também possuíam vilas; de acordo com Heródoto (2.98.I), a esposa do rei era dona de uma vila no Egito, a qual era responsável pela fabricação dos sapatos da rainha, e Parysatis, esposa de Dario II, era conhecida por ter vilas na Media (Xen. an. 2.4.27). Mulheres reais viajaram através do Império, não apenas como parte da comitiva do rei, mas também em seu próprio direito, visitando suas propriedades e residências particulares, acompanhadas de seus atendentes pessoais e funcionários. ${ }^{37}$

Utilizaremos a sigla abreviada em inglês PFT para os Tabletes da fortificação de Persépolis.

HALLOCK, R. Persepolis Fortification Tablets. Chicago: The University of Chicago Press, 1969. p. 7.

HALLOCK, op. cit., p. I.

BROSIUS, M. A History of Ancient Persia: The Achaemenid Empire. Hoboken, NJ: Wiley-Blackwell, $202 \mathrm{I}$. p. 43 . 


\section{REVISTA ANGELUS NOVUS}

Dois casos apresentados nos PFTs são de Irdabama e de Irtašduna - ou Artystone, em grego, segundo Matthew Stolper ${ }^{38}$ - citada previamente. Essas duas mulheres fariam parte da Corte de Dario I, segundo a autora citada acima, sendo Irtašduna esposa do mesmo. ${ }^{39}$ Brosius (2006, p.43) nos aduz que Irdabama possuía sob sua tutela uma força de aproximadamente 500 trabalhadores.

Imagem I Tablete da Fortificação de Persépolis 1002 referente ao pagamento de trabalhadores de Irdabama

\section{PF 1002}

${ }^{19}$ ME 66 'šE. ${ }^{1}$ BAR.lg kur-min ${ }^{2} \mathrm{~m}$.Ku-un-tuk-ka-na m.kur-taš ${ }^{3} \mathrm{~m}$. Tur-mi-ri-ya-ip f.Ir${ }^{4}$ da-ba-ma-na h.Nu-ku-sa-5an-ti-iš gal-lu-ma du-ma-6iš ${ }^{1} 6$ d'.rTu.lg ha-tu-ma ${ }^{7}$ d.Tu-Tirma '-raš d.Sa-a-8kur-ri-zi-iš d(!)".Kar-ma-ba-taš edgo " d.Tar-na-ba-zi-iš d. ${ }^{10} \mathrm{Ka}$-ir-ba-ši-ya d.Ba-

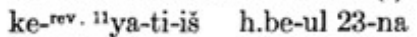

${ }^{12} 15$ m.ruh.lg 3 du-man-ba ${ }^{13} 12 \mathrm{~m}$.'pu'-hu $2 \frac{1}{2}{ }^{\prime} \mathrm{KI}+\mathrm{MIN}{ }^{1}{ }^{14} 5 \mathrm{~m} . \mathrm{KI}+\mathrm{MIN} 2{ }^{\prime} \mathrm{KI}+\mathrm{MIN}{ }^{1}$

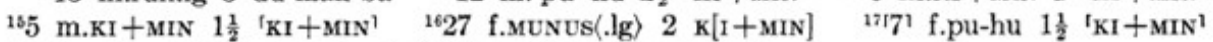
184 'f.KI+ MIN' $^{1} 1{ }^{\prime} \mathrm{KI}+\mathrm{MIN}$ ' u. edge ${ }^{19} \mathrm{PAP} 70(+) ' 5$ m.kur-taš

(d.) ITU.lg' 1-na 1 ME 61 š[E.BA]R.lg 'du-išstb

1-6966 (BAR of) grain, supplied by Kuntukka, Turmiriyan workers of (the woman) Irdabama received as rations (at) Nukusantis. ${ }^{m-11}$ For a period of 6 months, the second, third, fourth, fifth, sixth (and) seventh, 23rd year.

${ }^{12} 15$ men receive $3 .{ }^{13-15} 12$ boys receive $2 \frac{1}{2}, 5$ boys receive 2,5 boys receive $1 \frac{1}{2} .{ }^{16} 27$ women receive $2 .{ }^{17-187}$ girls receive $1 \frac{1}{2}, 4$ girls receive $1 .{ }^{19}$ Total 75 workers.

(For) 1 month they received 161 (BAR of) grain.

Tablet form Ed $(5.4 \times 3.8 \times 1.8)$. Seal 135 left edge.

- d(1) wr. as Aš.

b Last five signs wr. on r. edge.

Fonte HALLOCK, R. Persepolis Fortification Tablets. Chicago: The University of Chicago Press, 1969. p. 290.

Imagem 2 Tablete da Fortificação de Persépolis iI84 referente ao recebimento de suprimentos para Irtašduna que serão repassados para trabalhadoras.

\section{PF 1184}

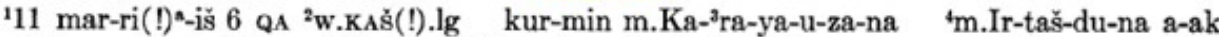

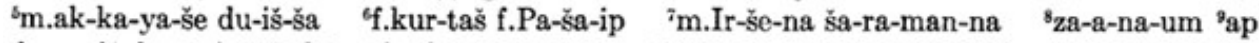
du-nu-iš-da edro ${ }^{10} 2$ d.' ITu.lg' ha-'tu-ma' ${ }^{\text {rev. }}{ }^{11} \mathrm{~d}$.Tu-ri-ma-'ra' ${ }^{12} \mathrm{~d}$.Sa-a-'kur'-ri-zi-iš

${ }^{13}$ PAP 1 ME 16 f .kur-taš ${ }^{14}$ un-ra-'na' d.rTt.lg-man-na ${ }^{15} 20$-ir-'ma'-ak-ki ${ }^{16} \mathrm{~h}$.Hi-da-li

${ }^{1-911.6}$ marriš (of) beer, supplied by Karayauza, Irtašduna and his companion(s) received, and gave (it as) zãnam to Paša (women) workers, whose apportionments are set by Iršena. ${ }^{10-12}$ For a period of 2 months, the second (and) third.

${ }^{13-15} \mathrm{~A}$ total (of) 116 (female) workers monthly (receive) each $\frac{1}{2 \gamma}$ (marris). ${ }^{16}$ (At) Hidali.

Tablet form Ad $(4.2 \times 4.0 \times 1.8)$. Seal 211 rev., another seal left edge.

" ri(!) wr. as gu.

$b f$ is preceded by an erasure.

Fonte HALLOCK, Richard. Persepolis Fortification Tablets. Chicago: The University of Chicago Press, 1969. p.340. 
Richard Hallock ${ }^{40}$ nos chama atenção de que nos tabletes em que há registro de rações mensais regulares para grupos de trabalhadores, o número de mulheres é superior ao de homens e crianças de ambos os sexos. O autor ainda nos aduz que normalmente o pagamento das mulheres é menor do que dos homens, mas que podemos encontrar mulheres, em alguns casos, recebendo mais que pessoas do sexo masculino, provavelmente por serem supervisoras ou possuírem "habilidades especiais". Essa questão do pagamento maior devido ao gênero e sobre a quantidade de mulheres ser superior ao de homens, pode ser atestada no primeiro exemplo, o PF IOO2. Nesta tabuinha há um total de 75 trabalhadores recebendo o pagamento de rações, mas as mulheres são a maioria, havendo, em números por gênero e idade: 27 mulheres, Is homens, 22 meninos e II meninas.

No PF 1002, Kuntukka fornece $966 \mathrm{BAR}^{41}$ de grãos para pagamento de trabalhadores Turmiriyan da mulher Irdabama, em Nukusantiš, por um período de 6 meses. De acordo com o PFT, durante I mês eles receberam I6I BAR de grãos. A interpretação é dificultada no momento em que se vê quanto os trabalhadores receberam de acordo com seu gênero e idade. Por exemplo: Is homens receberam 3, mas nenhuma medida é especificada (provavelmente a medida é o BAR). Ainda assim, não sabemos se esse valor é válido para os is homens no total ou se cada um deles recebeu 3 $\mathrm{BAR}$ [?] de grãos, pois o documento não precisa. Entretanto, é notável que o grupo de 27 mulheres recebeu apenas $2 \mathrm{BAR}$ [?], mostrando que, mesmo sendo a maioria da força de trabalho neste PFT, e que possivelmente possuíam filhos, ${ }^{42}$ ainda recebiam menos que os homens.

Já o PFT II84 é sobre o pagamento de II.6 marriš³ de cerveja para II6 mulheres trabalhadoras de Paša. A cerveja foi fornecida por Karayauza e entregue para seus companheiros e Irtašduna, que deram as cervejas para as trabalhadoras, cuja repartições são definidas por Iršena. Aparentemente, receberam as cervejas por um período de 2 meses, com as 116 mulheres recebendo $1 / 20$ marris. Nesse caso, temos a medida relacionado à quantidade de cerveja recebida, mas não sabemos se cada uma recebeu essa quantia ou se esse valor é para o total de mulheres.

40 HALLOCK, R. Persepolis Fortification Tablets. Chicago: The University of Chicago Press, 1969. p. 5.

4I De acordo com a Tabela 2, de Adrian David Bivar, I hōfan equivale a 0.932 litros; I BAR equivale a ro hōfan, medindo assim 9.32 litros (BIVAR, A. D. Weights and Measures: i. Pre-Islamic Period. Encyclopedia Iranica, Is mar. 20Io. Disponível em: «https://iranicaonline.org/articles/weights-measures-i\#prettyPhoto». Acesso em: 25 set. 202I).

42 De acordo com Hallock, as rações para mães eram pagamentos únicos, com mães de meninos recebendo, de forma regular, o dobro de rações do que mães de meninas (HALLOCK, op. cit., p. 5-6).

43 De acordo com a Tabela 2, de Adrian David Bivar, I kapithēequivale a 2.33 litros; I marriš equivale a 4 kapithe, medindo assim, 9.32 litros (BIVAR, op. cit.). 


\section{REVISTA ANGELUS NOVUS}

Ambos os PFTs são ótimos exemplos para demonstrar que as mulheres de origem nobre, possuíam trabalhadores sob suas ordens, e que, possivelmente, o fornecimento das comódites para o pagamento dessa força de trabalho pode ter partido delas mesmas, o que mostra possuírem autonomia, como Brosius atestou na citação acima. Mas os tabletes também demonstram que a mulher de camada social mais baixa, na Pérsia Aquemênida, mesmo que estrangeira, como aparenta ser o caso no PF Ioo2, possuíam espaço dentro da sociedade, exercendo atividades econômicas e não sendo relegadas à reclusão da casa, em comparação como se acreditava ${ }^{44}$ ser com as mulheres atenienses do século V AEC, as quais, segundo Fábio Lessa, os deveres femininos em Atenas, seriam referentes ao

exercício das atividades domésticas; submissão ao homem; abstinência aos prazeres do corpo, considerados como masculinos; o silêncio; a fragilidade e a debilidade; a reprodução de filhos legítimos - preferencialmente do sexo masculino; a vida sedentária e reclusa no interior do oîkos; e a sua exclusão da vida social, pública e econômica. ${ }^{4}$

Essa ideia de reclusão é aplicada no conceito do harém real, o qual alguns autores helênicos, como Plutarco, acreditavam existir:

Pois o povo bárbaro é terrivelmente ciumento de tudo o que diz respeito aos prazeres do amor, de modo que é a morte para um homem, não apenas subir e tocar uma das concubinas reais, mas até mesmo em viagem passar pelas carroças em que elas são transportadas. ${ }^{46}$

Contudo, é necessário destacar a análise de Lloyd Llewellyn-Jones, ${ }^{47}$ que adota uma posição sutilmente diferente, buscando se afastar da ideia orientalista do harém, ${ }^{48}$

44 "A ideia da exclusão das mulheres gregas da organização antiga foi validada por especialistas no campo, no domínio francófono notadamente, com as fórmulas bem conhecidas de Pierre Vidal-Naquet designando a cidade como um 'clube de homens' ou as de Nicole Loraux afirmando que não havia 'cidadã' e sim 'ateniense', e que 'o cidadão ateniense podia então ser simplesmente definido como aquele que, dos dois lados, tinha pais cidadãos: o seu próprio pai e o pai de sua mãe" (CUCHET V. "Quais direitos políticos para as cidadãs da Atenas clássica?” Revista Hélade, v. 4, n. I, 2018 p.I45).

45 LESSA, F. Mulheres de Atenas: Mélissa - do Gineceu à Ágora. Rio de Janeiro: Mauad X, 2010. p. I5.

46 PLUTARCH. “Artexerxes”. Plutarch Lives, Vol. XI. Cambridge, MA: Harvard University Press, I954. XXVII.I, p. 193 .

47 LLEWELlyn-JONES, L. King and Court in Ancient Persia, 559 to 33 I BCE. Edimburgh: Edimburgh University Press, 2013. p. 97

48 "Enquanto o harém pode ser um espaço físico, uma área identificável de um palácio ou casa que é usado por mulheres - e por crianças, eunucos e homens privilegiados, pelo que consta - um harém também pode se referir a mulheres e seus parentes de sangue agrupados; um harém não necessariamente precisa de um espaço de definição. 'Harém' tem em sua essência o árabe háram, significando 'proibido' ou 'tabu'. Por implicação, significa um espaço que o acesso geral é proibido (ou limitado) e que a presença de certos indivíduos ou certos tipos de comportamento são proibidos. $\mathrm{O}$ fato de que quartos privados em uma residência doméstica e, por extensão, suas ocupantes femininas, também são referidos como um 'harém', vem da prática islâmica de restringir o acesso a esses aposentos, especialmente para homens não relacionados por parentesco de sangue com essas mulheres. A palavra 'harém' é, portanto, um termo de respeito, evocando pureza religiosa e honra pessoal, e como Hugh Kennedy enfatizou, na prática real do Oriente Médio, um governante usaria 'harém'

I2 • ano XII, n. I7, 202I • ISSN 2I79-5487 
de que este seria algo desprovido de liberdade e isolamento, onde as mulheres passariam o dia preparando-se para servir aos desígnios sexuais masculinos. ${ }^{49}$ A ideia de "liberdade” está ligada à de "visibilidade", entretanto, essa é uma construção ocidental pós-Revolução Industrial que de modo algum tem a ver com a Antiguidade. Tanto no Oriente como na Antiga Grécia, ${ }^{5 \circ}$ uma mulher de classe abastada não sentia honra em ser vista publicamente, havendo aí o verdadeiro prestígio e autoridade:

Isso é particularmente relevante para o conceito otomano de harém: embora não fosse divino, um sultão otomano, "a sombra de Deus na Terra”, criou um espaço sagrado ao redor de sua presença física, e porque o sultão vivia dentro do harém, o próprio espaço físico assumiu uma dimensão adicional de inviolabilidade. Em muitos aspectos, um monarca persa Aquemênida se assemelhava ao governante otomano: ele também era o único representante de Deus na terra, o todo-poderoso Ahuramazda, e, como tal, enfatizou sua remoção dos mortais comuns, confinando-se fisicamente nas áreas domésticas de seu palácio, longe do olhar de seus súditos, exceto por períodos de audiência pública formal. Assim, eu diria que o termo "harém" é totalmente aplicável à prática doméstica real Aquemênida. ${ }^{\text {st }}$

Para alguns autores, essa ideia de liberdade entre as mulheres persas teria sido a razão para a decadência do Império. Por exemplo, Heleen Sancisi-Weerdenburg afirma, segundo Takuji Abes ${ }^{2}$, que "Ctésias em particular foi de grande importância para a noção de estabelecimento de decadência persa, devido ao fato de que sua obra descreve a Corte persa como um ambiente repleto de vida no harém, eunucos, luxúria e intriga"s3.

para se referir a todas as suas mulheres e a todos os outros indivíduos sob sua proteção imediata - filhos, irmãos, cortesãos e escravos - em outras palavras, as personagens que compunham sua corte interna" (LLEWELlYN-JONES, L. King and Court in Ancient Persia, 559 to 33 B BCE. Edimburgh: Edimburgh University Press, 2013. p. 97).

49 "Uma imagem da vida privada do rei chega a nós através de Diodoro, que descreve a seguinte cena: 'Todas as noites [as concubinas] desfilavam sobre o leito do rei para que ele pudesse escolher aquela com quem se deitaria naquela noite' (XVII. $\left.77.7^{*}\right)$. O texto sugere que a cada noite uma nova concubina se juntava à cama do Grande Rei" (BRIANT, P. From Cyrus to Alexander: A History of the Persian Empire. Winona Lake, IN: Eisenbrauns, 2002. p. 282).

so É importante ressaltar a assertiva de Junqueira de que “em vista das novas descobertas arqueológicas e dos novos estudos a respeito da atuação das mulheres atenienses, percebemos que essas regras de conduta não eram sempre seguidas por parte das mulheres" (JUNQUEIRA, N. Imagens da mulber grega: Heródoto e as pinturas em contraste. Tese (Doutorado) - Instituto de Filosofia e Ciências Humanas, Universidade Estadual de Campinas, Campinas, 20II. p. 76).

5I LLEWELLYN-JONES, L. "Eunuchs and the royal harem in Achaemenid Persia (559-33I BC)". TOUGHER, S. (Org.). Eunuchs in Antiquity and Beyond. Swansea: The Classical Press of Wales, 2002. p. 25.

52 ABE, T. “Ctesias' Persica: Persian Decadence in Greek Historiography”. In: NAKAI, Y; CARAFA, Paolo (Org.). Memory of the Past and It's Utility: Nation, State, Society and Identity. Roma: Scienze e Lettere, 2014. p. 37 .

53 "Ctésias pode [...] ser creditado com algo realmente novo, algo a ser encontrado em seu trabalho, na minha opinião, pela primeira vez na historiografia europeia: o conceito de Oriente. O termo Oriente provoca 


\section{REVISTA ANGELUS NOVUS}

Para Dominique Lenfant, essa ideia de decadência persa teria surgido por volta da metade do século IV AEC, sendo "antes de tudo, uma visão grega, desenvolvida em escritos sem valor histórico e, sobretudo, sem qualquer pretensão real deste tipo". ${ }^{54}$ Entretanto, Lenfant levanta a hipótese de que essa concepção veio dos próprios persas em fins do século V AEC por Ciro, o Jovem, e sua propaganda sobre as deficiências e fraquezas de seu irmão, Artaxerxes II, como Rei, na intenção de destroná-lo, com o Pérsica de Ctésias exercendo apenas um papel secundário. Os atenienses souberam aproveitar esse discurso e reorganizaram-no em seu próprio benefício, segundo a autora. A historiadora francesa ainda ressalta que Heródoto e Ésquilo não manifestaram em seus textos a ideia de declínio, pois estes apenas opuseram Xerxes aos Reis que o precederam, dentro do contexto preciso do confronto entre gregos e persas:

Nada prova, de fato, que Ctésias viu nas revoltas um sinal de "decadência": primeiro, porque estas estão presentes desde muito cedo em sua história da Pérsia; segundo, pois estas sempre são suprimidas; enfim, porque os gregos estão longe de ter percebido as revoltas como sinais de "decadência”, quer tenham irrompido dentro do Império Persa, como a revolta da Jônia, ou no mundo grego, como as cidades do Império ateniense do século $\mathrm{V}$ a.C.ss

Então, pode-se entender que essa conceituação da decadência persa não é válida atualmente, pois, de acordo com as ideias de Lenfant, ${ }^{56}$ essa visão de declínio apenas surgiu num momento muito posterior ao conflito Greco-Pérsico. O Império continuou a possuir influência militar e diplomática sobre os povos vizinhos, mesmo após as Guerras Greco-Pérsicas, até sua fase final, demonstrando que essa ideia de deterioração pode estar equivocada ao ser aplicada em todo o período Aquemênida. ${ }^{57}$

\section{Um ensaio comparado entre Heródoto e Ctésias}

Apesar de não caber mais no debate historiográfico a noção de declínio do Império Aquemênida causado, em parte, pelas mulheres, é notório que a imagem delas em

associações de haréns, eunucos, luxo, intrigas. Tem conotações de suavidade, proximidade, indulgência e falta de rigor. Para resumir: significa efeminação" (LLEWELLYN-JONES, L.; ROBSON, J. Ctesias: History of Persia. London: Routledge, 2010. p. 26).

54 LENFANT, D. "La «décadence» du Grand Roi et les ambitions de Cyrus le Jeune: aux sources perses d'un mythe occidental?”. Revue des Études Grecques, v. II4, n. 2, 200I. p. 407-409.

55 LENFANT, op. cit., p. 43I.

56 LLENFANT, op. cit., p. 4I3.

57 ABE, T. "Ctesias' Persica: Persian Decadence in Greek Historiography”. In: NAKAI, Y; CARAFA, Paolo (Org.). Memory of the Past and It's Utility: Nation, State, Society and Identity. Roma: Scienze e Lettere, 20I4. p. 35 .

I4 $\bullet$ ano XII, n. I7, 202I $・$ ISSN 2I79-5487 
alguns dos textos literários helênicos possuía uma conotação negativa, como a de serem objetos cujo dono é o Rei, como pudemos perceber no subtítulo acima, em citações de Diodoro e Plutarco, por exemplo. Mas como é a imagem dessas mulheres reais nos textos de Heródoto e Ctésias? Desta forma, iremos primeiro visualizar algumas passagens de ambos os autores, a começar por Heródoto.

$\mathrm{O}$ autor das Histórias nos conta, em seu nono livro, que Xerxes se apaixonou pela esposa de seu irmão, Masistes. O Grande Rei, então, elabora um plano para obtê-la para si, casando seu filho com a filha de Masistes e essa mulher. Contudo, acaba por desistir da mulher mais velha, cortejando e conquistando a mais jovem, chamada Artaÿnte, agora esposa de seu filho, Dario. ${ }^{8}$ Desta maneira se desdobra o seguinte acontecimento, segundo o autor:

A esposa de Xerxes, Amestris, teceu e deu a ele um grande manto de cores vivas, maravilhoso de se ver. Xerxes estava satisfeito e foi à Artaÿnte vestindo-o; e estando satisfeito com ela também, ele a ordenou que pedisse o que ela teria em troca de seus favores, pois ele não negaria nada quando pedisse. Por isso - pois ela e toda sua casa estavam condenadas ao mal - disse a Xerxes: “Queres dar-me tudo que te peço?", e ele prometeu e jurou, supondo que ela pedisse qualquer coisa menos isso; mas quando ele jurou, ela pediu ousadamente por seu manto. Xerxes esforçou-se muito para recusá-la, por nenhuma razão, exceto por temer que Amestris pudesse ter uma prova clara de que ele estava fazendo o que ela já adivinhara; e ele ofereceu-lhe cidades, e ouro em abundância e um exército para ninguém além dela comandar. [...] Mas como ele não podia convencê-la, ele deu-lhe o manto; e ela, regozijando-se muito com o presente, foi exibir-se com suas melhores roupas. Amestris soube que ela possuía o manto; mas quando soube a verdade, sua raiva não era com a garota; ela supôs que a mãe da menina era culpada e que isso era de seu feitio, então foi a esposa de Masistes que ela planejou destruir. Ela esperou, portanto, até que Xerxes, seu marido, desse seu banquete real. Este banquete é servido uma vez por ano, no aniversário do rei; [...] naquele dia (e em nenhum outro) o rei unge sua cabeça e faz presentes aos persas. Aguardando por esse dia, Amestris, então, desejou a Xerxes que a esposa de Masistes fosse dada a ela. Xerxes considerou um ato terrível e perverso desistir da esposa de seu irmão, e isso também quando ela não tinha culpa do suposto ato; pois ele conhecia o propósito do pedido. No entanto, sendo Amestris instantânea, e a lei o restringindo (pois neste banquete real, na Pérsia, toda benção solicitada deve necessariamente ser concedida), ele consentiu muito contra a vontade e entregou a mulher à Amestris; então, ordenando que ela fizesse o que ela quisesse, ele mandou chamar seu irmão [...]. Entretanto, enquanto Xerxes falava com seu irmão, Amestris mandou chamar os guardas de Xerxes e usou a esposa de Masistes com muita crueldade; ela cortou os seios IX.Io8. 


\section{REVISTA ANGELUS NOVUS}

da mulher e os jogou para os cachorros, e seu nariz e orelhas e lábios da mesma forma, e cortou sua língua, e mandou-a para casa assim, cruelmente usada. ${ }^{59}$

Ctésias, por sua vez, narra em seu Pérsica sobre Parysatis, mãe de Artaxerxes II. Deve-se lembrar, como afirmado anteriormente, que os fragmentos da obra do autor de Cnido foram selecionados e interpretados por autores posteriores a ele, como Plutarco e Fócio, por exemplo, que o usaram para seus próprios fins. Isto posto, observemos algumas passagens de Ctésias.

Segundo Fócio, ${ }^{60}$ Ctésias diz que Ciro, o Jovem, se revoltou contra o seu irmão, Artaxerxes II, na intenção de destroná-lo, comandando um exército composto tanto por gregos quanto persas, com a parte grega sendo liderada por Clearchus de Esparta. O rapaz atacou o exército do Rei, conquistando a vitória, mas perdendo sua vida na batalha. Ciro teve seu corpo mutilado por Artaxerxes II, que ordenou que sua cabeça e a mão que o ferira fossem arrancadas de seu corpo, e estas foram carregadas em triunfo. O Rei, acreditando que foi ele quem matou o irmão em batalha, e fazendo questão que todos pensassem e dissessem o mesmo, envia presentes a Mitradates, que fora o primeiro a atacar Ciro. Entretanto, o Cariano que atingiu o joelho do rapaz e o derrubou do cavalo, pediu presentes e recebeu apenas um prêmio de consolação por relatar boas notícias, pois Artasyras foi o primeiro a relatar a morte de Ciro. ${ }^{61}$

É importante ressaltar que Parysatis amava o jovem falecido mais que seu filho entronado, assim diz Ctésias, segundo Plutarco, ${ }^{62}$ pois este fato é importante para a sucessão das subsequentes ocorrências:

Mas, por estupidez, o Cariano deixou que um sentimento perfeitamente ordinário o dominasse. Pois ele foi corrompido, ao que parece, por sua atual boa fortuna e persuadido a reivindicar coisas que estavam além dele. Ele não aceitou os presentes por relatar boas novas, e ficou indignado, pedindo testemunhas e gritando que era ele mesmo e ninguém mais quem matara Ciro e que estava sendo injustamente privado de sua glória. Quando o Rei ouviu isso, ficou muito irritado e ordenou que o homem fosse decapitado. Mas sua mãe, que estava presente, disse: "Não deixe este Cariano desgraçado ir embora assim, meu Rei! Ele receberá sua recompensa pelo que se atreveu a dizer de mim, em vez disso". O Rei o entregou e Parysatis ordenou aos algozes que prendessem o homem e o colocassem na

59 HERODOTUS. The Persian Wars, Volume I: Books I-II. Cambridge, MA: Harvard University Press, 1920. IX.IO9-II2.

60 PHOTIUS. The Library of Photius: Volume I. London: Macmillan, 1920. p. I07-I08.

6I PLUTARCH. Plutarch Lives, Vol. XI. Cambridge, MA: Harvard University Press, 1954. 14.5-6; LLEWELLYN-JONES, L.; ROBSON, J. Ctesias: History of Persia. London: Routledge, 20Io. p. 205.

62 PLUTARCH, op. cit., p. I3I.

I6 $\bullet$ ano XII, n. 17, 202I • ISSN 2179-5487 
tortura por dez dias, depois arrancassem seus olhos e derramassem bronze derretido em suas orelhas até que morresse. . $^{3}$

Pouco tempo depois, diz Ctésias, ainda de acordo Plutarco, ${ }^{64}$ Mitradates teve um péssimo fim por um semelhante ato de estupidez. Ele foi convidado para um jantar onde estavam presentes os eunucos do Rei e da Rainha-Mãe, adornado com ouro e roupas que Artaxerxes II lhe dera. E quando começaram a beber, Sparamizes, o eunuco mais poderoso de Parysatis começa a bajular o homem, que já estando bêbado, alega que se mostrou digno de coisas maiores e mais belas do Rei devido às suas ações no dia da batalha. Contudo, este era um plano do eunuco para expô-lo na frente de todos, que estava aguardando o vinho o deixar falante e de guarda baixa. Sparamizes o provoca falando que não há muita glória em achar a sela de um cavalo, e Mitradates diz sem rodeios que ele não arremessou sua lança à toa, e que foi ele quem causou o ferimento pelo qual Ciro morreu. Sparamizes conta à Parysatis, que diz a Artaxerxes II, que fica irado por se sentir exposto e roubado de sua vitória, ordenando que o homem fosse morto pela tortura dos barcos. Mitradates agonizou por 17 dias, até finalmente falecer.

O último episódio também envolve um eunuco, segundo Ctésias conta, conforme Plutarco. ${ }^{65}$ Masabates, um dos eunucos do Rei, foi quem cortou a cabeça e a mão de Ciro, o Jovem e Parysatis o visava para completar sua vingança. Ela, sendo uma mulher naturalmente inteligente e exímia jogadora de dados, pois jogava com Artaxerxes II com certa frequência, antes da guerra, arquitetou o seguinte esquema:

Ela se reconciliou com ele depois da guerra e, ao invés de fugir de seus afetos, voltou a jogar com ele e até cooperou em suas aventuras eróticas, auxiliando-o com sua presença. [...] Um dia, Parysatis pegando Artaxerxes sem nada para fazer e começando a vagar preguiçosamente, desafiou-o para um jogo de dados com uma aposta de I.ooo dáricos. E ela fez com que ele ganhasse o jogo e ela entregasse o ouro. Fingindo que estava irritada e ansiosa para reaver o que perdeu, sugeriu outro jogo, desta vez a aposta sendo um eunuco. E o rei consentiu. Eles concordaram que cada um deles poderia excluir seus cinco eunucos mais confiáveis, mas dos demais, o vencedor poderia escolher quem quisesse e o perdedor entregaria: essas eram as condições de seu jogo de dados. Parysatis se dedicou seriamente ao jogo e jogou com determinação e, como os dados pareciam também cair a seu favor, ela venceu e reivindicou Masabates: pois ele não estava entre os eunucos que Artaxerxes havia excluído. E antes que as suspeitas do Rei fossem levantadas, ela o entregou pessoalmente aos algozes, a quem ela ordenou que o esfolassem vivo, empalassem seu corpo de lado em três estacas e separassem sua pele esticada. Quando isso foi feito, o Rei achou intolerável e

63 PLUTARCH. Plutarch Lives, Vol. XI. Cambridge, MA: Harvard University Press, I954. I4.7-IO; LLEWELLYN-JONES, L.; ROBSON, J. Ctesias: History of Persia. London: Routledge, 2oro. p. 206.

64 PLUTARCH, op. cit., I5.I-I6.7; LLEWELLYN-JONES, L.; ROBSON, J., op. cit., p. 206-207.

65 PLUTARCH, op. cit., I7.I-9; LLEWELLYN-JONES, L.; ROBSON, J., op. cit., p. 207-208. 


\section{REVISTA ANGELUS NOVUS}

ficou zangado com ela, mas ela fingiu ignorância e com um sorriso disse: "Como você é doce! Fico feliz por você ficar zangado por causa de um velho eunuco inútil! Eu, por outro lado, perdi I.ooo dáricos nos dados e aceitei minha perda e não disse uma palavra”. E assim o Rei, embora se arrependesse de ter sido enganado dessa forma, segurou sua língua.

As duas personagens femininas centrais desta análise, Amestris e Parysatis, quando comparadas entre si, são postas como muito inteligentes e pacientes; entretanto, também são colocadas como vingativas, manipuladoras, opressoras, possessivas e ardilosas. Suas virtudes, então, são sobrepostas pelas características negativas, pois estas são mostradas de maneira a não medir esforços para chegar ao seu objetivo, nesse caso, a vingança. Pode-se notar essa característica da manipulação e ardilosidade em Heródoto, quando Amestris aguarda o banquete de aniversário do Rei, pois ele está preso à lei em não poder descumprir qualquer pedido feito a ele, por pior que seja. Já em Ctésias, vê-se como Parysatis manipulou cada situação a seu favor para se vingar daqueles que clamavam ter matado seu filho predileto e aquele que mutilou o corpo falecido de Ciro, enganando o próprio Rei para atingir seu desejo de vingança.

Essa aspiração vingativa é motivada justamente pela possessão. No caso de Amestris, o sentimento por seu marido, Xerxes. E na conjuntura de Parysatis, é o sentimento de posse por seu filho mais novo, entrando numa série de assassinatos de membros da Corte e pessoas leais ao Rei, segundo Stateira, esposa de Artaxerxes II. ${ }^{66}$ Este, por sua vez, não toma providências sobre essa situação em específico, pela mesma razão de Xerxes: temor. Xerxes sente medo de sua esposa e, no caso de Artaxerxes, o receio é da mãe. E esse pavor de ambos os Reis vem justamente da opressão que ambas as Rainhas exercem sobre marido e filho, respectivamente. Xerxes teme a esposa por saber do que ela é capaz, enquanto Artaxerxes II teme a mãe, primeiramente por ser sua progenitora e, em segundo lugar, por ser facilmente manipulado por ela, não notando a manipulação sofrida nas situações do Cariano, Mitradates e de Masabates, e não a retrucando em momento algum. Em relação a Rainha-Mãe, Llewellyn-Jones aduz: ${ }^{67}$

$\mathrm{Na}$ Pérsia e Oriente Próximo em geral, embora não se esperasse que a mãe do rei exercesse o poder oficial, ela poderia ganhar influência política por meio da manutenção cuidadosa dos favores de seu filho (usando lisonja, de acordo com Plutarco, Moralia 174b) como consequência de suas próprias ambiçôes e habilidades pessoais. Em outras palavras, o poder da mãe do rei era indireto. Mesmo assim, ela poderia influenciar o filho na formulação de políticas. [...] No entanto, o poder real que a mãe do rei poderia exercer era limitado e ela agia apenas com o consentimento do rei, embora, estritamente na esfera doméstica, ela possa ter recebido carta branca para tomar decisões por conta própria. Ctésias implica que a mãe do rei tinha controle

66 PLUTARCH. Plutarch Lives, Vol. XI. Cambridge, MA: Harvard University Press, 1954. 17.9; LLEWELLYNJONES, L.; ROBSON, J. Ctesias: History of Persia. London: Routledge, 2oIO. p. 208.

67 LLEWELLYN-JONES, L.; ROBSON, J., op. cit., p. III.

I8 • ano XII, n. 17, 202I • ISSN 2179-5487 
sobre o comportamento dentro do harém, policiando seus costumes e punindo os crimes de traição da família, eunucos, médicos da corte e outros funcionários do harém. No entanto, a mãe de um rei agia às vezes sem o consentimento de seu filho, e suas ações poderiam até ser traidoras, mas ela sofria as consequências. ${ }^{68}$

Para Richard McNeal, ${ }^{69}$ Heródoto busca escrever sua obra de forma honesta, mas este acaba por narrar sentimentos e ações que os antigos gregos possuíam e faziam, como se fossem dos povos não helenizados, e isso acaba por dizer mais sobre o pensamento de Heródoto e dos antigos gregos do que dos persas e quaisquer outros povos mencionados na obra. A alegação de $\mathrm{McNeal}$ também pode convergir para a obra de Ctésias, mas “como o texto original do Pérsica não sobreviveu, não podemos saber quantas palavras ou páginas o autor dedicou a cada período ou ocorrência individual através de sua narrativa", ${ }^{70}$ deixando-nos reféns da visão dos autores posteriores ao médico de Cnido, dificultando em perceber até onde é o pensamento de Ctésias e até em que ponto é são as ideias desses outros autores.

\section{Conclusão}

Heródoto e Ctésias, possuem uma visão acerca das mulheres como "vingativas, masculinizadas e impulsivas", ${ }^{71}$ utilizando de suas narrativas para criar a comparação e separação entre "civilizados" e "bárbaros", denotando em suas obras o que ocorreria, em suas concepções, com as sociedades das Pólis helênicas caso as mulheres recebessem mais poder político e liberdades do que deveriam, pois seriam traiçoeiras, segundo a mentalidade masculina da Hélade. Entretanto, devemos ressaltar que os autores helênicos possuíam uma visão tendenciosa e com pré-conceitos acerca do feminino, tanto em Atenas quanto na Pérsia Aquemênida, havendo essa retratação negativa e pejorativa acerca das mulheres, principalmente quando não helênicas.

Desta forma, ao olharmos apenas para as produções helênicas, podemos criar uma visão tendenciosa sobre determinados povos, civilizações, gêneros e segmentos sociais,

68 Segundo Plutarco, Ctésias declara que Parysatis é exilada para a Babilônia após assassinar por envenenamento a esposa de Artaxerxes II, Stateira, com o Rei afirmando que enquanto sua mãe viver, ele não verá a Babilônia novamente (PLUTARCH. "Artaxerxes". Plutarch Lives, Vol. XI. Cambridge, MA: Harvard University Press, 1954. 19.I-IO; LLEWELLYN-JONES, L.; ROBSON, J. Ctesias: History of Persia. London: Routledge, 2oio. p. 212-213).

69 MACNEAL, R. "The Brides of Babylon: Herodotus I.I96”. Historia: Zeitschrift für Alte Geschichte, v. 37, n. I, 1988. p. 54-7I.

70 ABE, T. “Ctesias' Persica: Persian Decadence in Greek Historiography”. In: NAKAI, Y; CARAFA, Paolo (Org.). Memory of the Past and It's Utility: Nation, State, Society and Identity. Roma: Scienze e Lettere, 20I4. p. 44 .

7I JUNQUEIRA, N. Imagens da mulher grega: Heródoto e as pinturas em contraste. Tese (Doutorado) Instituto de Filosofia e Ciências Humanas, Universidade Estadual de Campinas, Campinas, 20II. p. 77. 


\section{REVISTA ANGELUS NOVUS}

sendo importante verificar toda e qualquer documentação disponível sobre o tema abordado pelos autores da Hélade, em especial se for relacionado à outra sociedade. Logo, pensando na hipótese de Lenfant ${ }^{72}$ sobre os atenienses se aproveitarem da propaganda de Ciro, o Jovem contra seu irmão em benefício próprio, podemos considerar que os atenienses criaram essa ideia de ruína a partir das liberdades e poderes femininos, para negativar a imagem persa, mas também impedir que, de alguma forma, isso ocorra em sua própria sociedade.

Assim, as semelhanças comparativas nestas obras em relação ao modo em que estas mulheres Reais são descritas, apesar das vivências e temporalidades diferentes entre os autores, "nos alerta para a ideia de que as mulheres teriam um comportamento definido dentro da sociedade ateniense, e que deveria ser adotado nas famílias e respeitado pelas próprias mulheres", ${ }^{73}$ sendo a imagem da mulher persa da Corte Aquemênida, o modelo falho de comportamento feminino em comparação com o modelo de comportamento da mélissa. Entretanto, como nos atestou Cuchet, ${ }^{74}$ as mulheres atenienses possuíam direitos e liberdades como cidadãs, excetuando-se o direito político, não sendo reclusas ao oikos.

Sob este prisma, juntamente com os eunucos, as mulheres persas teriam se tornado responsáveis pela educação, criando sucessores no luxo e sem disciplina, sendo esta a base da decadência do Império persa, ${ }^{75}$ de acordo com esses autores helênicos, além de exercerem poderes que não caberiam a uma mulher na mentalidade ateniense, ou seja, exercer influência política.

Contudo, como notamos através dos PFTs, além de ser algo atestado por autores persianistas, como Maria Brosius, Takuji Abe, entre outros, a mulher possuir um papel social influente e de destaque em determinada sociedade, não causaria o declínio da mesma, e isto estaria relacionado a outros fatores que merecem um estudo próprio. Mas, possuindo uma educação e visão de mundo baseada na cultura helênica, tais autores, como Ctésias, que apesar de ter vivenciado por alguns anos a vida da Corte Persa, iriam reproduzir tais discursos propagandísticos, os quais se espalhariam pela Hélade, com uma probabilidade maior de tal disseminação ocorrer nos locais que eram

72 LENFANT, D. "La «décadence» du Grand Roi et les ambitions de Cyrus le Jeune: aux sources perses d'un mythe occidental?”. Revue des Études Grecques, v. II4, n. 2, 200I.

73 JUNQUEIRA, N. Imagens da mulher grega: Heródoto e as pinturas em contraste. Tese (Doutorado) Instituto de Filosofia e Ciências Humanas, Universidade Estadual de Campinas, Campinas, 20Ir. p. 74.

74 CUCHET, V. "Quais direitos políticos para as cidadãs da Atenas clássica?” Revista Hélade, v. 4, n. I, 2018.

75 ABE, T. "Ctesias' Persica: Persian Decadence in Greek Historiography”. In: NAKAI, Y; CARAFA, Paolo (Org.). Memory of the Past and It's Utility: Nation, State, Society and Identity. Roma: Scienze e Lettere, 20I4. p. 50.

$20 \cdot$ ano XII, n. I7, 202I $\bullet$ ISSN 2179-5487 
dominados ou possuíam mais contato com o Império Aquemênida, por uma possível insatisfação com o domínio ou ameaça persa.

No caso do autor de Cnido, sua obra pode ter sido alterada pelos autores posteriores a ele, como mostramos a partir de Dominique Lenfant ${ }^{76}$ na introdução deste artigo, assim como Lloyd Llewellyn-Jones e James Robson ${ }^{77}$ demonstraram em seu livro com passagens retiradas destes autores posteriores, como Fócio e Plutarco, para exemplificar, reproduzindo tais ideias em suas próprias obras, provavelmente. Heródoto, por sua vez, viajou por diversas localidades escrevendo suas Histórias sobre o que via e ouvia de terceiros, havendo um risco de esses relatos estarem distorcidos pelas visões e ideias das pessoas sobre o Império Aquemênida, além do próprio Heródoto poder alterar a narrativa para seu próprio fim. Sob este prisma, conclui-se que deve se tomar cuidado ao abordar tais composições, pois as visões de mundo de seus autores, além da "terceirização" da produção literária, como no caso de Ctésias, prejudica, em partes, a análise do que é real e do que é fantasioso sobre as mulheres da realeza na Pérsia Aquemênida.

76 LENFANT, D. "La «décadence» du Grand Roi et les ambitions de Cyrus le Jeune: aux sources perses d'un mythe occidental?". Revue des Études Grecques, v. II4, n. 2, 200I.

77 LLEWELLYN-JONES, L.; ROBSON, J. Ctesias: History of Persia. London: Routledge, 20Io. p. 36-45. 